\title{
Study of defects in chemical vapor deposited diamond films by cross-sectional cathodoluminescence
}

\author{
A. Cremades, F. Domínguez-Adame, and J. Piqueras \\ Departamento de Fisica de Materiales, Facultad de Físicas, Universidad Complutense, 28040 Madrid, \\ Spain
}

(Received 22 March 1993; accepted for publication 8 July 1993)

\begin{abstract}
Cathodoluminescence (CL) in the scanning electron microscope has been used to study the upper surface and cross-sectional samples of chemical vapor deposited diamond films. The CL emission is mainly localized at the grain boundaries of the columnar grains. The concentration of dislocation related radiative centers is higher in boundaries parallel to the growth axis than in boundaries parallel to the sample surface. The opposite occurs with the concentration of centers related to the presence of nitrogen.
\end{abstract}

\section{INTRODUCTION}

Different luminescence techniques have been used in the last few years to characterize diamond films grown by chemical vapor deposition (CVD). In particular cathodoluminescence (CL) has been applied to detect defects and impurities in diamond films and to provide information on their spatial distribution. ${ }^{1-4}$ Some of the prominent $\mathrm{CL}$ bands in the visible range have been discussed in Ref. 1 and a band peaked at about $430 \mathrm{~nm}$ has been attributed to dislocations. ${ }^{1,3}$ On the other hand a broad luminescence band, called band $\mathrm{A}$, with sample dependent peak energy in the blue-green region has been observed in natural and synthetic diamonds as well as in CVD films. ${ }^{5}$ It has been proposed $^{1,3}$ that the dislocation related band could be in fact the blue part of the A -band if donor-acceptor pairs are localized at dislocations. In the green region a complex band peaked at about $530 \mathrm{~nm}$ is thought to be associated with centers containing nitrogen atoms and vacancies. ${ }^{1} \mathrm{CL}$ imaging in the transmission electron microscope $e^{3,4}$ has shown that the $430 \mathrm{~nm}$ band is related to dislocations while no particular correlation of green emission with microstructure was observed. Robins et al. ${ }^{1}$ concluded, from their CL observations in the scanning electron microscope (SEM) of CVD films, that centers related to nitrogenvacancy complexes and to dislocations are primarily located in the near-surface regions adjacent to $\{100\}$ crystal faces. Yacobi et al. ${ }^{2}$ observed by CL-SEM strong inhomogeneities in CL intensities in different regions of their CVD films indicating strong variations in impurity and defect concentration.

Previous electron microscope-CL studies, as those mentioned above, refer mainly either to measurements in plan view specimens of the diamond films or to analysis of defects and impurities of localized regions. However, SEM-CL studies of side view samples could provide information on the film structure and defect distribution along the growth axis. This is of interest for a more complete characterization of the films as well as in film growth problems. For this reason, $C L$ investigation of the upper surface and of cross sections of CVD diamond films has been carried out in this work.

\section{EXPERIMENTAL METHOD}

CVD films from Norton Co. with a thickness of about $300 \mu \mathrm{m}$ were used. For CL measurements the samples were mounted in the scanning electron microscope either with the upper surface or with a lateral fracture surface exposed to the electron beam. The samples were observed in the emissive and CL modes in a Hitachi S-2500 scanning electron microscope at accelerating voltages of $20-25 \mathrm{keV}$, at temperatures between 90 and $300 \mathrm{~K}$. An optical lens was used to concentrate the light on a photomultiplier attached to a window of the microscope. In some cases optical filters were interposed to obtain monochromatic images. To record spectra a light guide feeding the light to an Oriel 78215 computer controlled monochromator was used. Spectra were recorded under different focusing conditions of the electron beam on the sample and were corrected to include the system spectral response.

\section{RESULTS AND DISCUSSION}

Figure 1 shows the CL image of the upper surface of the film. The strong variations of the CL emission from different regions of the sample are similar to those reported by Yacobi et $a l^{2}$ and have no clear correspondence with the secondary electron image. Figure 2 shows the CL spectra from the upper surface obtained with focused and defocused electron beam, respectively, at low temperature. The same features are apparent in the room temperature spectra but with a lower signal to noise ratio. The blue emission observed in the spectrum of Fig. 2(a) has often been associated with dislocations. In particular, there is a strong correlation of blue $C L$ with grains or regions of greatest dislocation density. ${ }^{3}$

Interaction volume increases with defocusing. For this reason, the emission of centers with low concentration becomes detectable while saturation of other recombination paths occurs as discussed in Ref. 6. In Fig. 2(a) the shoulder at $510 \mathrm{~nm}$ is due to the contribution of emission at longer wavelengths. By defocusing, the relative contribution of this emission increases and the band peaked at 535 $\mathrm{nm}$ appears [Fig. 2(b)]. This band is probably the green band peaked at different positions, between 530 and 580 $\mathrm{nm}$, which has been attributed to centers containing nitro- 


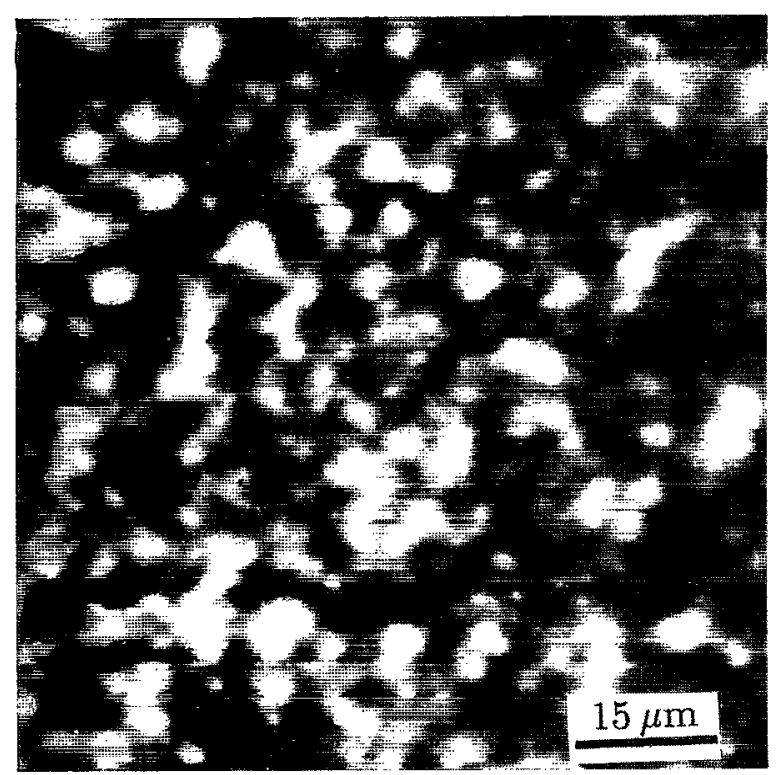

FIG. 1. CL image of the upper surface of the diamond film.

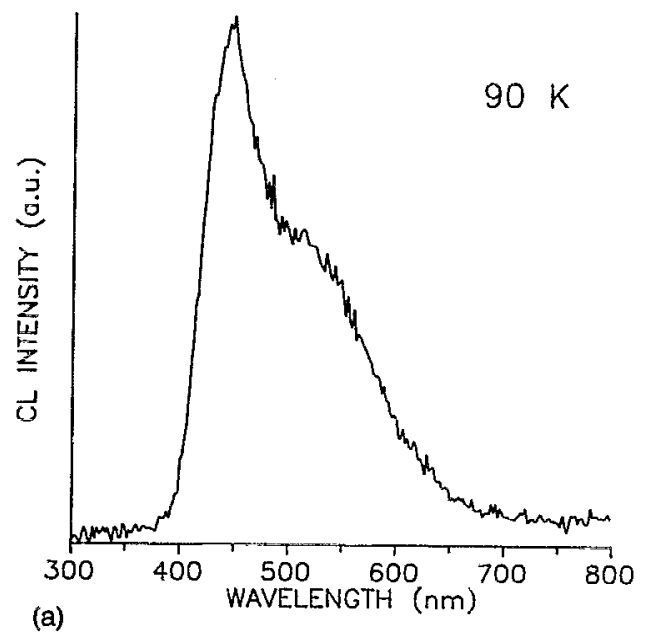

(a)

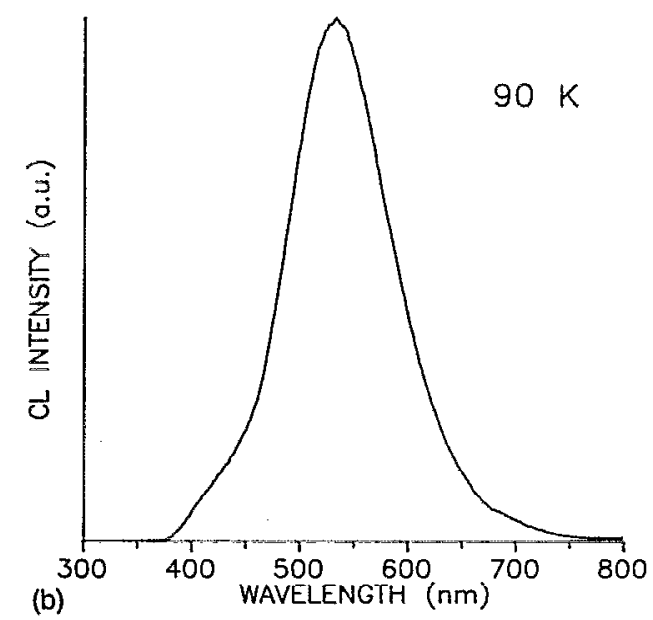

FIG. 2. CL spectra of the upper surface with (a) focused and (b) defocused beam.

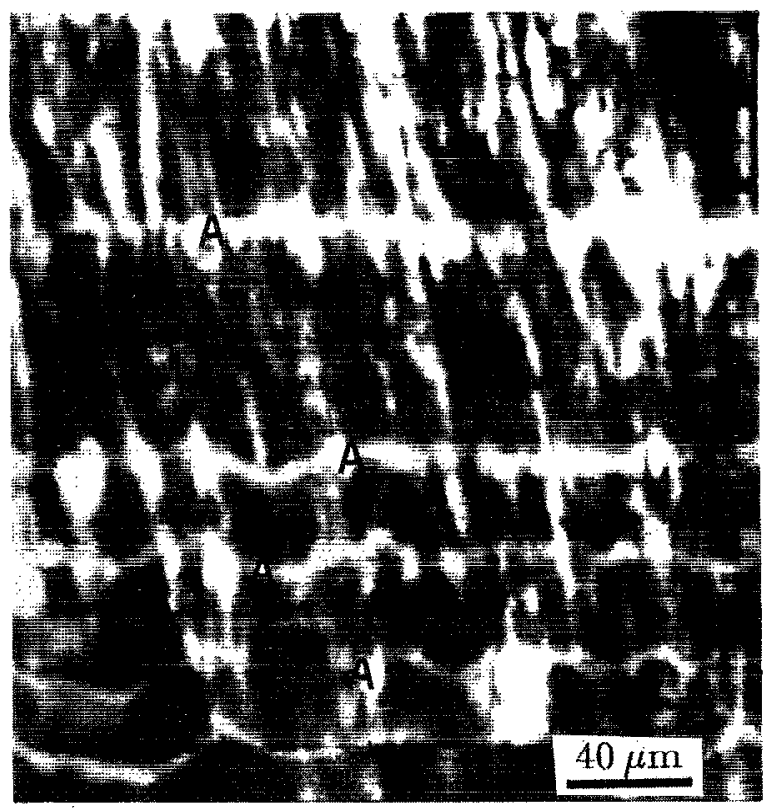

FIG. 3. Panchromatic CL image of the lateral surface of the film.

gen atoms and vacancies. The $C L$ contrast observed in Fig. 1 would be due to an inhomogeneous distribution of dislocations and nitrogen related centers.

Figure 3 is the total (panchromatic) CL image of the lateral surface of the sample. The basic pattern observed consists of bright lines (some of them marked $\mathrm{A}$ in the micrograph) whose main direction is parallel to the upper sample surface and bright lines mainly directed in the perpendicular direction. This structure corresponds to the columnar grain structure often described in CVD diamond samples. ${ }^{7,8}$ The bright lines would then basically represent grain boundaries. However, lines perpendicular to the surface do not appear as well defined and probably include some features produced during cleavage. Figure 4 shows the spectrum recorded with the electron beam fixed on a point of a line parallel to the sample surface, hereafter

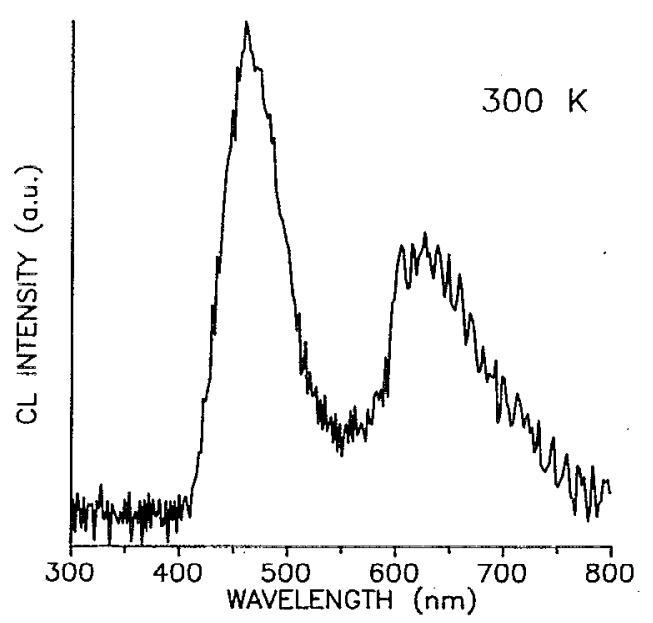

FIG. 4. CL spectrum at a point of a line parallel to the sample surface. 


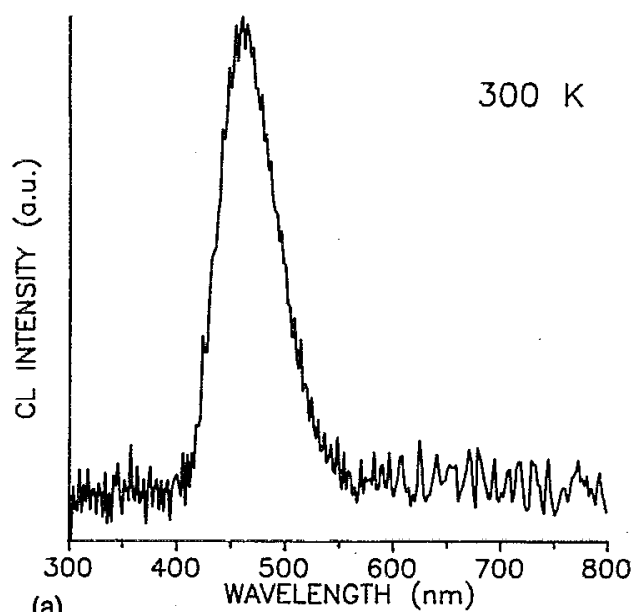

(a)

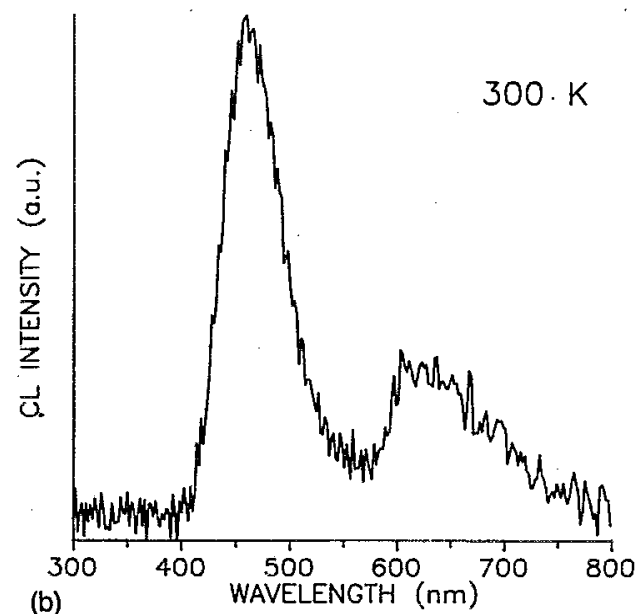

(b)

FIG. 5. CL spectra at a point of a line parallel to the growth direction with (a) focused and (b) defocused beam.

referred to as A lines. Similar spectra with peaks at 460 and $630 \mathrm{~nm}$ are obtained with focused or with defocused electron beam. Figure 5 shows spectra recorded on a point of a line parallel to the growth direction, hereafter called B lines. With focused electron beam [Fig. 5(a)] only the 460 $\mathrm{nm}$ peak is observed while by defocusing [Fig. 5(b)] an additional emission peaked at $630 \mathrm{~nm}$ appears due to the same saturation effect described above. The different luminescence properties in A and B lines are also observed in the monochromatic images of Fig. 6, in which optical band pass filters were used. In Fig. 6(a), corresponding to a 630 nm filter, most of the emission arises from $A$ lines and in Fig. 6(b) obtained with a $470 \mathrm{~nm}$ filter, the emission from $B$ lines dominates. The distance between $A$ lines increases from the lower sample surface. This effect agrees with previous observations ${ }^{9-11}$ that the grain size measured along the growth direction of diamond films increases along the growth axis with larger grains being observed near the upper surface.

These results show that the CL emission is mainly localized at the growth boundaries and that the recombination centers in the boundaries along the $\mathrm{A}$ lines are different than in the lateral boundaries. The concentration of

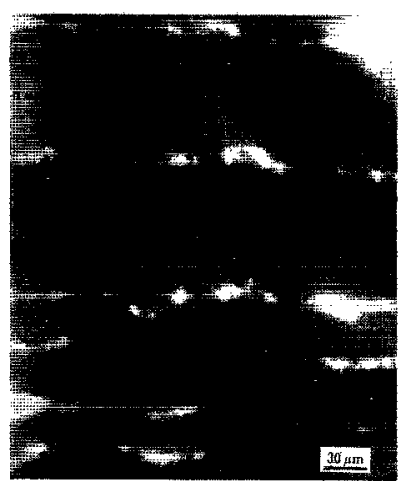

(a)

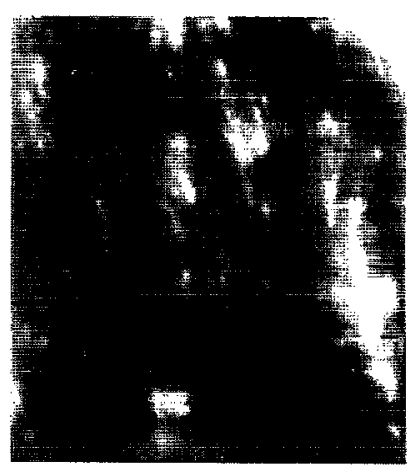

(b)
FIG. 6. CL images of the lateral surface obtained with (a) $630 \mathrm{~nm}$, (b) $470 \mathrm{~nm}$ bandpass filter.

dislocation related centers, responsible for blue emission, is higher in B boundaries than in A boundaries and the opposite occurs with the concentration of centers related to the $630 \mathrm{~nm}$ band. The latter band has been reported in photoluminescence and CL studies ${ }^{1,12,13}$ and is attributed to the presence of nitrogen complexed with vacancies.

\section{CONCLUSIONS}

In the scanning electron microscope of cross-sectional samples of CVD diamond films CL allows for a visualization of grain boundaries, and reveals features of defect distribution not observed in plan-view samples. Radiative centers related to dislocations as well as nitrogen related centers are mainly localized at the boundaries. The relative concentrations of both centers depends on the boundary direction-parallel or perpendicular to the sample surface- of the columnar grains.

\section{ACKNOWLEDGMENTS}

This work has been supported by DGICYT (Project PB-1017). Thanks are due to Dr. E. Wolfgang for drawing our attention to the $\mathrm{CL}$ cross sectional measurements.

${ }^{1}$ L. H. Robins, L. P. Cook, E. N. Farabaugh, and A. Feldman, Phys. Rev. B 39, 13367 (1989).

${ }^{2}$ B. G. Yacobi, A. R. Badzian, and T. Badzian, J. Appl. Phys. 69, 1643 (1991).

${ }^{3}$ R. J. Graham, T. D. Moustakas, and M. M. Disko, J. Appl. Phys. 69, 3212 (1991).

${ }^{4}$ R. J. Graham and K. V. Ravi, Appl. Phys. Lett. 60, 1310 (1992).

${ }^{5}$ H. Kawarada, K. Nishimura, T. Ito, J-i. Suzuki, K. S. Mar, Y. Yokota, and A. Hiraki, Jpn. J. Appl. Phys. 27, L683 (1988).

${ }^{6}$ H. C. Casey and J. S. Jayson, J. Appl. Phys. 42, 2774 (1971)

${ }^{7}$ H. A. Hoff, C. J. Craigie, E. Dantsker, and C. S. Pande, Appl. Phys. Lett. 59, 1693 (1991).

${ }^{8}$ K. V. Ravi, C. A. Koch, H. S. Hu, and A. Joski, J. Mater, Res. 5, 2356 (1990).

${ }^{9}$ A. R. Badzian, T. Badzian, R. Roy, R. Messier, and K. E. Spear, Mater. Rcs. Bull. 23, 531 (1988).

${ }^{10}$ J. E. Graebner, S. Jin, G. W. Kammlot, J. A. Heris, and L. F. Gardiner, Nature 359, 401 (1992).

${ }^{11}$ S. Jin, J. E. Graebner, T. H. Tiefel, and G. W. Kammlot, Diamond and Related Materials 2, 1038 (1993)

${ }^{12}$ T. Evans, S. T. Davey, and S. H. Robertson, J. Mater. Sci. 19, 2405 (1984).

${ }^{13}$ A. T. Collins and S. H. Robertson, J. Mater. Sci. Lett. 4, 681 (1985) 
Journal of Applied Physics is copyrighted by the American Institute of Physics (AIP). Redistribution of journal material is subject to the AIP online journal license and/or AIP copyright. For more information, see http://ojps.aip.org/japo/japcr/jsp

Copyright of Journal of Applied Physics is the property of American Institute of Physics and its content may not be copied or emailed to multiple sites or posted to a listserv without the copyright holder's express written permission. However, users may print, download, or email articles for individual use. 
Journal of Applied Physics is copyrighted by the American Institute of Physics (AIP). Redistribution of journal material is subject to the AIP online journal license and/or AIP copyright. For more information, see http://ojps.aip.org/japo/japcr/jsp 